\title{
Penanaman Sikap Mitigasi Kebakaran Siswa SD Joseph Khatulistiwa Sintang dengan Permainan "Gamikar"
}

\author{
Nelly Wedyawati ${ }^{1}$, Antonius Edy Setyawan ${ }^{2}$ \\ ${ }^{1}$ Prodi PGSD, STKIP Persada Khatulistiwa \\ ${ }^{2}$ Prodi Pendidikan Komputer, STKIP Persada Khatulistiwa \\ 1nellywedyawati@ymail.com, \\ 2edysetyawan.200286@gmail.com
}

\begin{abstract}
ABSTRAK
Kabupaten Sintang merupakan daerah tingkat II yang berada di wilayah propinsi Kalimantan Barat. Dengan luas wilayah $21.635 \mathrm{~km} 2$, sebagian besar wilayahnya berupa kawasan hutan dan lahan. Data dari dinas kebakaran kabupaten Sintang menunjukkan bahwa bencana kebakaran baik kebakaran lahan dan hutan maupun kebakaran di pemukiman warga menjadi bencana yang hampir terjadi setiap tahun terutama saat musim kemarau. Tahun 2015 merupakan bencana kebakaran yang terbesar di kota Sintang. Dinas pemadam kebakaran telah berupaya untuk mencegah terjadinya bencana tersebut. Beberapa upaya telah dilakukan antara lain berupa himbauan maupun sosialisasi ke masyarakat. Namun hal tersebut belum bisa dilakukan secara maksimal. SD Joseph Khatulistiwa Sintang merupakan salah satu SD yang belum pernah mendapatkan materi tentang mitigasi kebakaran. Oleh alasan inilah, penulis merasa perlu untuk mengangkat tema kegiatan ini dengan memilih SD Joseph Khatulistiwa Sintang sebagai sasaran mitra kegiatan Pengabdian kepada Masyarakat (PkM). Metode yang digunakan dalam PkM ini adalah berupa kegiatan pembelajaran melalui sebuah permainan yang disebut dengan Gamikar. Kegiatan direncanakan akan dilaksanakan selama 2 hari. Luaran yang menjadi target dari kegiatan ini adalah peningkatan pemahaman siswa dalam mitigasi bencana kebakaran. Adanya peningkatan dilihat dari perbandingan pada pengukuran awal dan pengukuran akhir dari kegiatan PkM.
\end{abstract}

Kata Kunci: kebakaran, mitigasi, gamikar, SD, sintang

\section{ABSTRACT}

Sintang Region is an area of level II in the Kalimantan Barat (West Borneo). The wide area of the land are $21.635 \mathrm{~km}^{2}$, most the area are forest and soil. Sintang Region Fire Department was stated that fire disaster, including soil, forest and settlement fire always became similar problem every year, especially at dry season. On the year 2015, fire was the huge disaster that happened in Sintang Region. Fire Department already tried hard to prevent that fire disaster. Socialization and Education already done by Fire Department but that was not effective and efficient. Sintang Region is an area of level II in the Kalimantan Barat (West Borneo). The wide area of the land are $21.635 \mathrm{~km}^{2}$, most the area are forest and soil. Sintang Region Fire Department was stated that fire disaster, including soil, forest and settlement fire always became similar problem every year, especially at dry season. On the year 2015, fire was the huge disaster that happened in Sintang Region. Fire Department already tried hard to prevent that fire disaster. Socialization and Education already done by Fire Department but that was not effective and efficient. SD Joseph Khatulistiwa in Sintang is one of the elementary schools that has never received material on fire mitigation. For this reason, the writer needs to take up the theme of this activity by choosing SD Joseph Khatulistiwa Sintang as a target partner for Community Service activities (PkM). The method used in this PkM is learning activities through games called Gamikar. The approved activities will be carried out for 2 days. The target output of this activity is an improvement in the students' understanding of disaster mitigation. There were improvements seen from the initial and final measurements of PkM activities.

Keywords: fire disaster, mitigation, gamikar, elementary school, sintang 
PENDAHULUAN

Kebakaran hutan dan lahan (karhutla) di Pulau Kalimantan terjadi hampir setiap tahun dengan intensitas yang cukup tinggi seiring dengan datangnya musim kemarau dan secara nyata telah menimbulkan berbagai dampak negatif pada semua tingkatan baik lokal nasional maupun regional. Luas lahan kritis di wilayah Pulau Kalimantan tahun 2010 mencapai sekitar $34,09 \%$ dari total luas lahan kritis di Indonesia. Berdasarkan data dari Data dan Informasi Bencana Indonesia (DIBI) BNPB, bencana alam yang paling dominan berpotensi terjadi di wilayah Kalimantan adalah bencana kebakaran hutan dan lahan, banjir, dan kekeringan. Akibatnya 1) Jarak pandang hanya berkisar 200-300 meter. Masyarakat yang berkendara terpaksa menggunakan masker agar terhindar dari bahaya asap, mata perih dan sesak nafas (Irawan, 2018). 2) Siswa Sekolah Dasar terpaksa diliburkan dan berdampak terganggunya proses pembelajaran. 3) Kebakaran juga telah mengakibatkan korban jiwa (Mirna, 2018). 4) Karhutla dipastikan berpengaruh besar terhadap perekonomian, Dari segi distribusi logistik asap pekat tentu menghalangi jarak pandang pengemudi yang mengangkut logistik. Kabut asap mengakibatkan jarak pandang berkurang. Sehingga beberapa usaha transportasi memutuskan tidak beroperasi. Sebab pengaruhnya terhadap inflasi berdampak sangat besar pada penyisihan harga komoditas yang sudah ditetapkan oleh pemerintah (Sari \& Junius, 2018).

Sederatan bukti tersebut menunjukkan bahwa masyarakat perlu adanya edukasi mitigasi bencana alam. Sesuai dengan amanat Pembukaan UUD 1945 bahwa NKRI bertanggung-jawab melindungi segenap bangsa Indonesia dan seluruh tumpah darah Indonesia. Memberikan perlindungan terhadap kehidupan dan penghidupan termasuk perlindungan atas bencana untuk menjadikan "Bangsa yang Tangguh Menghadapi Bencana". Bangsa yang tangguh bencana adalah bangsa yang mempunyai kemampuan dalam mengatasi bencana melalui adaptasi dalam membangun kembali kehidupan dengan cara yang lebih baik. Kesiapsiagaan dan tanggap darurat adalah penjaga gawang atau benteng terakhir untuk mengurangi risiko ketika pencegahan dan mitigasi belum bekerja dengan baik. Sangat penting bagi akademisi menjadi mitra nasional dalam penanggulangan bencana. Para akademisi dapat berperan dengan memaksimalkan pendidikan kebencanaan dalam pembelajaran. Salah satu upaya yang dapat dilakukan untuk meningkatkan pemahaman siswa terhadap mitigasi bencana yakni dengan pengadaan media pembelajaraan. Media pembelajaran memiliki kegunaan-kegunaan untuk memperjelas penyajian pesan agar tidak terlalu bersifat verbal dan mampu mengatasi keterbatasan ruang, waktu, daya indera, seperti objek yang terlalu besar dapat digantikan dengan gambar atau model, dan juga konsep yang terlalu luas dapat divisualisasikan dalam bentuk film/gambar. Anak usia SD berada pada tahap operasi kongkret yang dapat bernalar secara logis mengenai peristiwa konkret dan mengklasifikasikan objek dalam bentuk yang berbeda dengan cara menerapkan suatu contoh kongkret. Dengan demikian media boardgame merupakan media yang tepat dan efektif untuk menumbuhan sikap tanggap bencana kebakaran bagi anak dengan menampilkan konsep mitigasi kebakaran secara kongkret. Ketika bermain sebuah permainan anak dapat melakukan berbagai interaksi dan pengambilan keputusan dengan mempertimbangkan berbagai kondisi. Anak juga dapat mengubah keputusannya berdasarkan skenario tertentu yang tentunya melibatkan logika. Menurut (Henry, 2010) memainkan game, anak mengalami pengalaman yang jauh melebihi apa yang mereka dapatkan di kelas. Sehingga tujuan dari penelitian yang dilakukan penulis yaitu "merancang boardgame edukasi mitigasi kebakaran untuk anak sekolah dasar yang layak, valid dan efektif digunakan".

Game memiliki keuntungan edukasi dimana memiliki potensi positif yang besar sebagai media pendidikan disamping hiburan yang diberikan dan ada kemungkinan akan keberhasilan yang tinggi ketika sebuah game di desain untuk mengajarkan suatu materi atau skill yang spesifik (Griffiths, 2010). Game dapat dengan mudah menarik anak untuk memberikan perhatian dan konsentrasi yang penuh kepada apa yang disajikan. Game dapat melibatkan anak secara interaktif dan menawarkan petualangan, tantangan, serta berbagai masalah yang harus dicari penyelesaiannya tanpa konsekuensi yang nyata. Hal ini dapat memberikan stimulasi positif pada anak sehingga dapat lebih terlibat dan tertarik pada proses pendidikan yang berlangsung. Perancangan game board game mitigasi kebakaran menggunakan pendekatan belajar dan bermain. Metode belajar dan 
bermain akan membantu anak dalam meningkatkan kecerdasan otak beserta memperoleh ilmu mitigasi kebakaran. Pendekatan ini secara tidak langsung akan memberikan anak sebuah pengalaman belajar (Setyanugrah \& Setyadi, 2017). Menurut (Rismawati, 2002) bahwa dengan media pembelajaran berupa game, anak mampu meningkatkan kinerja motorik sehingga mereka dapat berpikir dan bertindak dengan benar dalam satu waktu.

SD Joseph Khatulistiwa merupakan salah satu Sekolah Dasar swasta yang terletak di pinggiran kota Sintang. SD tersebut merupakan SD yang belum pernah mendapatkan perhatian dari pihak terkait dalam hal mitigasi kebakaran. Pemberian materi mitigasi kebakaran dirasa cukup penting karena secara geografis letak SD Josep Khatulistiwa berada di sekitar area lahan yang sewaktu-waktu bisa terjadi kebakaran di musim kemarau berkepanjangan. Oleh sebab itu penulis merasa bahwa kegiatan PKM ini perlu dilakukan dengan menggunakan permainan Gamikar sebagai usaha menanamkan sikap mitigasi kebakaran bagi siswa SD Joseph Khatulistiwa Sintang.

\section{METODE KEGIATAN}

Metode pelaksanaan pengabdian ini dilaksanakan melalui pendekatan permainan yang bernama Gamikar. Prosedur permainan sudah tertuang di dalam cara bermain pada Gamikar. Peningkatan pemahaman dilaksanakan dengan menggunakan pertanyaan-pertanyaan yang dibagikan sebelum bermain Gamikar dan sesudah bermain Gamikar.

Tahapan pengabdian yaitu 1) tahapan persiapan, tahapan observasi awal mengenai permohonan ijin kepada pihak sekolah, survei jumlah siswa, mempersiapkan soal sebelum permainan, soal sesudah permainan dan survei minat siswa terhadap permainan. 2) tahap permainan, tahapan inti dari pengabdian, siswa dibagi ke dalam beberapa kelompok dan melakukan permainan sesuai dengan prosedur yang tertera pada buku panduan. 3) tahapan evaluasi, tahapan melakukan analisis hasil yang diperoleh dari jawaban soal sebelum dan soal sesudah. Peningkatan pemahaman mitigasi kebakaran dianalisis dengan rumus Ngain dengan pengambilan keputusan sesuai dengan tabel 1.

Tabel 1. Kategori peningkatan pemahaman mitigasi

\begin{tabular}{cc}
\hline Skor Normalized Gain & Interpretasi \\
\hline$-1.00<\mathrm{g}<0.00$ & Decrease \\
\hline $\mathrm{g}=0.00$ & Stable \\
\hline $0.00<\mathrm{g}<0.30$ & Low \\
\hline $0.30<\mathrm{g}<0.70$ & Average \\
\hline $0.70<\mathrm{g}<1.00$ & High \\
\hline
\end{tabular}

\section{HASIL \& PEMBAHASAN}

Dalam kegiatan PKM ini terdiri dari 3 tahapan yakni persiapan, permainan, dan evaluasi. Hasil dari tahapan-tahapan tersebut diuraikan sebagai berikut:

\section{Persiapan}

Pada tahapan persiapan, selain memohon ijin kegiatan kepada kepala sekolah, survey jumlah siswa yang penting lainnya adalah membuat soal untuk mengetahui bagaimana pemahaman siswa terhadap mitigasi kebakaran sebelum dan sesudah implementasi gamikar. Soal-soal berjumlah 27 pertanyaan yang berisi tentang materi mitigasi kebakaran. Pertanyaan disusun dari kisi-kisi materi mitigasi kebakaran yang sudah ditetapkan (Suherman, 2009). Kisikisi disajikan dalam tabel 2.

Tabel 2. Kisi soal pemahaman mitigasi kebakaran

\begin{tabular}{llc}
\hline \multicolumn{1}{c}{ Materi Pembelajaran } & \multicolumn{1}{c}{ Indikator Perilaku Siswa } & Jlh soal \\
\hline Teori terjadinya api & Mengetahui teori terjadinya api & 3 \\
\hline Pencegahan Kebakaran & Memahami teori pencegahan & 2 \\
\hline Cara penyelamatan dokumen & Mengetahui cara penyelamatan dokumen & 1 \\
\hline Penyebab kebakaran & Mengetahui penyebab kebakaran & 3 \\
\hline Kerentanan kebakaran & Mengetahui kerentanan kebakaran & 1 \\
\hline Jenis ancaman kebakaran & Mengetahui jenis ancaman kebakaran & 2 \\
\hline Tahap pengembangan api & Mengetahui tahap pengembangan api & 3 \\
\hline Proses kebakaran & Mengetahui proses kebakaran & 3 \\
\hline Penyelamatan diri ketika terjadi & Upaya penyelamatan diri ketika terjadi & 3 \\
\hline
\end{tabular}




\begin{tabular}{lll}
\hline kebakaran & kebakaran & \\
\hline $\begin{array}{l}\text { Lokasi penyelamatan diri yang terdekat } \\
\text { dan aman }\end{array}$ & $\begin{array}{l}\text { Mencari lokasi penyelamatan diri yang } \\
\text { terdekat dan aman }\end{array}$ & 1 \\
\hline Pertolongan luka bakar ringan & $\begin{array}{l}\text { Menerapkan pertolongan luka bakar } \\
\text { ringan }\end{array}$ & 1 \\
\hline $\begin{array}{l}\text { Pengertian luka bakar dan } \\
\text { pembagiannya }\end{array}$ & $\begin{array}{l}\text { Dapat mengidentika pengertian luka bakar } \\
\text { dan pembagiannya }\end{array}$ & 1 \\
\hline $\begin{array}{l}\text { Langkah-langkah pertolongan luka } \\
\text { bakar }\end{array}$ & $\begin{array}{l}\text { Dapat mengidentikasi langkah-langkah } \\
\text { pertolongan luka bakar }\end{array}$ & 1 \\
\hline $\begin{array}{l}\text { Alat dan bahan pertolongan pertama } \\
\text { pada luka bakar ringan }\end{array}$ & $\begin{array}{l}\text { Mengidentikasi alat dan baha pertolongan } \\
\text { pertama pada luka bakar ringan }\end{array}$ & 3 \\
\hline Pertolongan pertama & Mengetahui tujuan pertolongan pertama & 1 \\
\hline Penyebab luka bakar & Mengetahui sebab luka bakar & 1 \\
\hline Klasikasi luka bakar & Dapat mengklasikan luka bakar & 1 \\
\hline
\end{tabular}

Soal-soal disiapkan untuk dibagikan sebelum bermain dan sesudah bermain. Soal sebelum dan sesudah bentuk dan jenisnya sama hanya berbeda nomor. Persiapan berikutnya adalah angket respon bagi siswa untuk melihat bagaimana kategori minat siswa terhadap permainan Gamikar. Kisi-kisi angket respon siswa diuraikan dalam tabel 3.

Tabel 3. Kisi-kisi angket respon

\begin{tabular}{lllc}
\hline \multicolumn{1}{c}{ Kriteria } & & Indikator & Jmlh Pertanyaan \\
\hline Respon & 1. & Ketertarikan & 6 \\
Siswa & 2. & Materi & 6 \\
& 3. & Bahasa & 3 \\
\hline
\end{tabular}

Pelaksanaan acara berupa waktu dan tempat kegiatan adalah hasil kesepakatan antara kepala sekolah dan pengabdi yang disajikan dalam tabel 4 di bawah ini.

Tabel 4. Waktu dan tanggal kegiatan

\begin{tabular}{cc}
\hline Tanggal & Kegiatan \\
\hline 17 Agustus 2019 & Persiapan \\
\hline 18 Agustus 2019 & $\begin{array}{c}\text { Membagikan soal pemahaman } \\
\text { siswa sebelum bermain }\end{array}$ \\
\hline 18 Agustus 2019 & Bermain dengan Gamikar \\
\hline 18 Agustus 2019 & $\begin{array}{c}\text { Membagikan soal pemahaman } \\
\text { siswa sesudah bermain }\end{array}$ \\
\hline 19 Agustus 2019 & $\begin{array}{c}\text { Membagikan Angket Respon siswa } \\
\text { sesudah bermain }\end{array}$ \\
\hline 19 Agustus 2019 & Evaluasi Kegiatan \\
\hline
\end{tabular}

\section{Permainan}

Kegiatan permainan menggunakan media yang disebut sebagai Gamikar (Gambar 1). Gamikar adalah media yang dirancang sebagai sarana edukasi untuk meningkatkan pemahaman siswa terhadap mitigasi bencana kebakaran. Adapun prosedur dan temuan saat bermain diuraikan sebagai berikut:

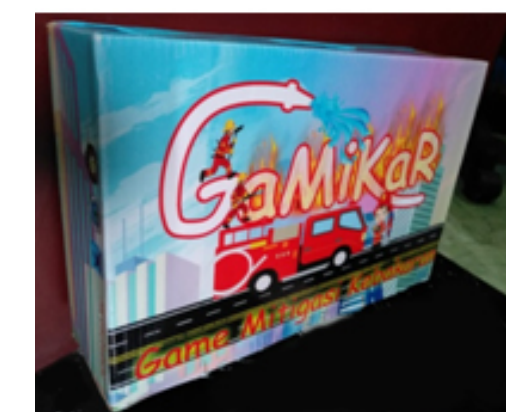

Gambar 1. Kotak Permainan Gamikar

\section{Prosedur Permainan}

1. Pemain berjumlah 2 - 4 orang.

2. Sebagai bekal awal, pemain berhak mendapatkan 2 Pin Air, 2buah APAR, 2 buah Hidran, dan 2 Kartu Call 113.

3. Pemain mengocok dadu secara bergiliran, angka yang terbanyak main dahulu. Permainan dimulai dari petak START.

4. Setelah itu Bidak pemain dijalankan bergiliran sesuai angka dadu ke petak menurut Urutan Nomor.

5. Setiap pemain berpeluang singgah ke ruterute perjalanan:

a. Rute Air: pemain berhak mendapatkan Pin Air

b. Rute Api: pemain harus sigap memadamkan Api dengan cara memadamkan dengan ketentuan

6. Kode A padamkan dengan Pin Air, APAR, \& Call 113.

7. Kode B padamkan dengan Pin Air dan Call 113.

8. Kode C padamkan dengan Pin Air \& Hidran\& Call 113.

a. Rute Bebas Parkir : Pemain berhak memarkirkan bidaknya. 
b. Rute hanya Nomor: Pemain harus menjawab pertanyaan dari kartu pertanyaan. (Jika jawaban benar makan pemain berhak mendapatkan 1 koin (Rp.))

9. 1 Koin (Rp) dapat ditukarkan dengan 2 Pin Air.

10. Apabila pemain berhasil memadamkan api dengan tepat sesuai dengan klasifikasinya maka pemain mendapatkan Pin API.

11. Jika Pemain salah dalam proses memadamkan api maka pemain diberikan denda kehilangan 1 Pin Air/1 Pin Api/1 pin (Rp).

12. Pemain dengan mengoleksi Pin Api terbanyak dialah sang Pemenang.

\section{Peralatan Gamikar}

Seperangkat Isi dalam kotak permainan berturut-turut adalah a) papan permainan, b) bidak, c) dadu, d) pin Air, e) pin Api, f) koin, g) kartu Pertanyaan dan h) kartu alat-alat pemadam kebakaran.

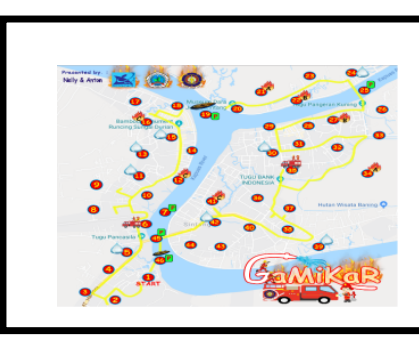

(a)

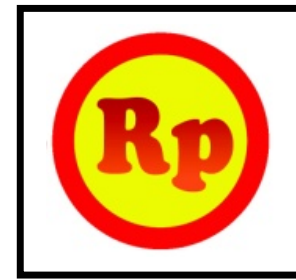

(f)

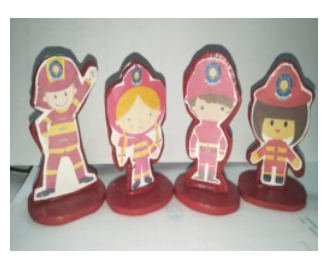

(b)

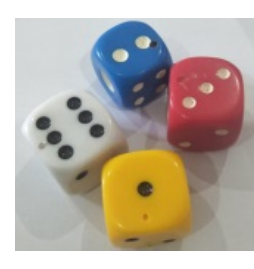

(c)

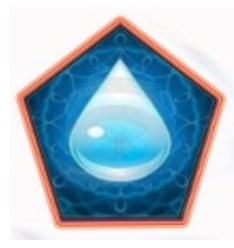

(d)

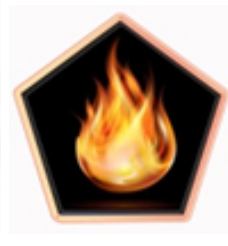

(e)

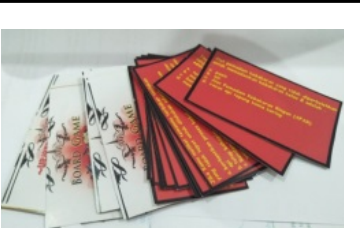

(g)

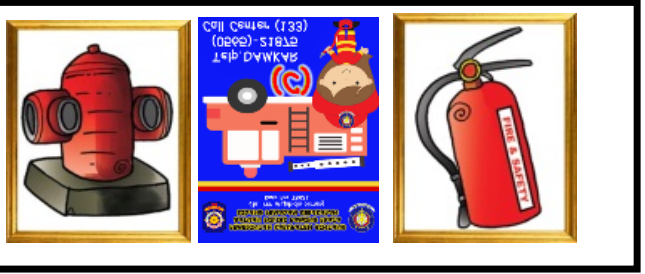

(h)

Gambar 2. Peralatan Gamikar

\section{Dokumentasi Permainan}

Dokumentasi kegiatan disajikan berturut-turut adalah a) Orientasi awal tentang cara bermain agar pemain lebih mudah bermain Gamikar.

b) Dokumentasi siswa mengisi soal pemahaman mitigasi bencana kebakaran sebelum sesi bermain Gamikar. c) Kegiatan
Bermain dengan Gamikar, bermain dan belajar tentang mitigasi bencana kebakaran. d) Dokumentasi siswa ketika mengisi soal setelah bermain. e) dokumentasi siswa mengisi angket respon siswa terhadap implementasi Gamikar. Dokumentasi kegiatan dapat dilihat pada gambar 3.

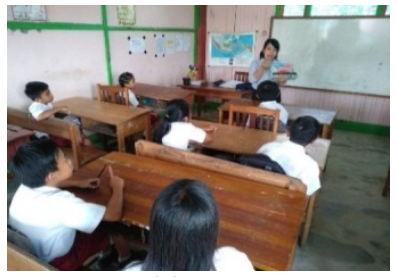

(a)

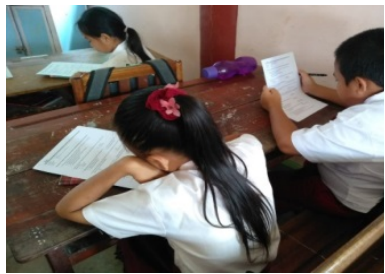

(b)

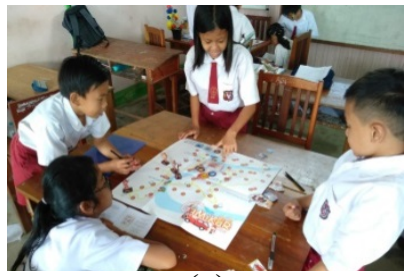

(c)

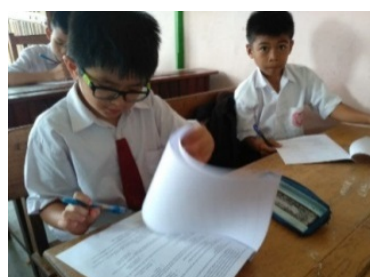

(d)

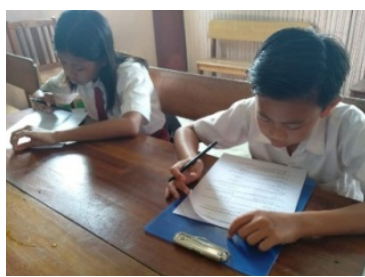

(e)

Gambar 3. Dokumentasi foto kegiatan PKM 


\section{Evaluasi}

a. Analisis pemahaman mitigasi kebakaran. Rekapitulasi hasil soal pemahaman mitigasi kebakaran disajikan dalam tabel 5 . Dari tabel diperoleh keterangan skor sebelum bermain gamikar adalah 100 dan skor sesudah bermain gamikar adalah 246. Skor maksimal yang dapat diperoleh siswa adalah 297. Dari perhitungan analisis dengan rumus Ngain diperoleh nilau 0.74 yang berkategori tinggi. Artinya ada perbedaan tinggi antara pemahaman siswa tentang mitigasi bencana kebakaran sebelum bermain gamikar dan setelahnya.

Tabel 5. Peningkatan pemahaman mitigasi kebakaran siswa.

\begin{tabular}{ccccc}
\hline $\begin{array}{c}\text { Skor } \\
\text { Sebelum } \\
\text { bermain }\end{array}$ & $\begin{array}{c}\text { Skor } \\
\text { Setelah } \\
\text { bermain }\end{array}$ & $\begin{array}{c}\text { Skor } \\
\text { Maks }\end{array}$ & $\begin{array}{c}\text { Normalized } \\
\text { Gain }\end{array}$ & kategori \\
\hline 100 & 246 & 297 & 0.74 & Tinggi \\
\hline
\end{tabular}

b. Analisis respon siswa

Rekapitulasi perolehan pembagian angket respon siswa terhadap permainan gamikar diperoleh skor masing-masing pada indikator ketertarikan, materi, bahasa berturutturut adalah $100 \%$. Skor ini menunjukkan bahwa siswa sangat berminat dengan permainan gamikar.

Tabel 6. Rekapitulasi penilaian siswa pada Gamikar

\begin{tabular}{cccc}
\hline \multicolumn{2}{c}{ \% Penilaian Siswa per Indikator } & Rerat \\
Ketertarikan & Materi & Bahasa & a \\
\hline 100 & 100 & 100 & 100 \\
\hline
\end{tabular}

Temuan dari serangkaian kegiatan Pengabdian pada Masyarakat yaitu permainan Gamikar mampu meningkatkan pemahaman siswa terhadap mitigasi bencana kebakaran dan permainan sangat diminati oleh para siswa. Model pembelajaran mitigasi bencana telah direspon positif oleh siswa SD (Wedyawati, 2017), tetapi perlu pengembangan edukasi kebencanaan yang lebih spesifikasi sehingga dalam riset ini bencana difokuskan pada bencana kebakaran yang disebabkan oleh alam dan manusia. Edukasi mitigasi kebakaran dikemas menarik dalam bentuk Gamikar yang dimainkan dengan metode permainan dengan tujuan agar produk diterima oleh guru, siswa dan masyarakat umum. Selain itu desain tampilan Gamikar yang meliputi tata tulis dan gambar menggunakan tata warna yang dominan disukai kalangan anak-anak seperti merah, kuning, hijau, biru sehingga anak SD semakin tertarik dalam memainkan Gamikar (Wedyawati \& Setyawan, 2019).

Permainan ini dapat digunakan oleh siswa untuk memperoleh perubahan sikap terhadap mitigasi kebakaran. Permainan direkomendasikan guna memperoleh generasi yang sikap tanggap bencana. (Cheng et al., 2019) melakukan penelitian yang sama dan menyimpulkan bahwa permainan papan berguna untuk memperoleh pengetahuan ilmiah terhadap bencana alam. Pengembang game board pendidikan telah menemukan permainan papan dapat meningkatkan kemampuan tingkat tinggi peserta didik dapat berupa: simulasi role-play, permainan berorientasi tujuan, memiliki aturan prosedural, terdapat mekanisme umpan balik, interaksi para pemain, dan putaran proses permainan berulang. Menurut para siswa permainan board game bermanfaat dalam mengajarkan strategi pencegahan bencana. Siswa ingin memainkan permainan lagi, dan siswa menunjukkan sikap lebih memperhatikan isu-isu seputar pencegahan bencana. Pembelajaran yang dimulai dengan permainan mampu merangsang pembelajaran bagi para peserta (Tsai et al., 2015)

\section{KESIMPULAN \& SARAN}

Simpulan yang dapat dituliskan dari kegiatan ini adalah permainan gamikar efektif meningkatkan pemahaman siswa SD Joseph Khatulistiwa dengan skor normalisasi gain 0.74 berkategori tinggi dan permainan gamikar sangat diminati oleh siswa dengan perolehan skor angket minat pada indikator ketertarikan, materi dan bahasa sebesar 100. Kesimpulan secara umum permainan Gamikar mampu menjadi permainan edukasi mitigasi kebakaran yang memberikan sensasi, siswa seolah menjadi seorang petugas pemadam kebakaran dan dituntut untuk bisa mengerti memahami apabila suatu saat terjadi kondisi darurat bencana kebakaran.

Dengan melihat hasil dari kegiatan pengabdian ini adalah, maka penulis memberikan beberapa saran yaitu; perlu adanya tindak lanjut dari pihak SD Joseph Khatulistiwa berupa penambahan materi mitigasi kebakaran ke dalam kurikulum pembelajaran yang sudah ada, permainan Gamikar perlu dikembangkan dan diujicobakan ke beberapa sekolah dasar lain terutama yang berada di kawasan rawan 
kebakaran agar semakin banyak siswa SD yang paham terhadap mitigasi bencana kebakaran.

\section{DAFTAR PUSTAKA}

Cheng, P.-H., Yeh, T.-K., Tsai, J.-C., Lin, C.R., \& Chang, C.-Y. (2019). Development of an Issue-SituationBased Board Game: A Systemic Learning Environment for Water Resource Adaptation Education. Sustainability, 11(5), 1341. https://doi.org/10.3390/su11051341

Griffiths, M. D. (2010). Computer game playing and social skills: A pilot study. 11.

Henry, S. (2010). Cerdas Dengan Game. PT Gramedia Pustaka Utama.

Irawan, K. (2018). Kabut Asap, Kualitas Udara Kota Pontianak Masuk Level Berbahaya.

https://regional.kompas.com/read/2018 /08/20/13443321/kabut-asap-kualitasudara-kota-pontianak-masuk-levelberbahaya

Mirna. (2018). Tiga Korban Diduga Kebakaran Lahan, Bocah 8 Tahun Meninggal. Tribun Pontianak. https://pontianak.tribunnews.com/2018 /08/13/tiga-korban-diduga-kebakaranlahan-bocah-7-tahun-meninggal

Rismawati. (2002). Menstimulus Perkembangan dan Kecerdasaan Otak Anak dengan Permainan.

Sari, N., \& Junius, A. (2018). INGAT..!! Kabut Asap Berpengaruh Besar Terhadap Perekonomian | Pro Kalbar. kalbar.prokal.co.

https://kalbar.prokal.co/read/news/226 1-ingat-kabut-asapberpengaruh\%20besar-terhadap-perekonomian

Setyanugrah, F., \& Setyadi, D. I. (2017). PERANCANGAN BOARD GAME SEBAGAI MEDIA PEMBELAJARAN MITIGASI KEBAKARAN UNTUK ANAK SEKOLAH DASAR USIA 8-12 TAHUN DI SURABAYA. Jurnal Sains dan Seni ITS, 6(1), 62-68. https://doi.org/10.12962/j23373520.v6 i1.22949

Suherman. (2009). Modul Ajar Pengintegrasian Pengurangan Resiko Kebakaran. Pusat Kurikuum Badan Penelitian dan Pengembangan Kementerian Pendidikan Nasional. https://www.slideshare.net/ninil/sdkebakaran-26-mei-2010

Tsai, M.-H., Wen, M.-C., Chang, Y.-L., \& Kang, S.-C. (2015). Game-based education for disaster prevention. $A I \&$ SOCIETY, 30(4), 463-475. https://doi.org/10.1007/s00146-0140562-7

Wedyawati, N. (2017). Developing Integrated Natural Sciences Disaster Mitigation Model for Elementary School Sintang. Journal of Educational Science and Technology, 3(2), 164-172.

Wedyawati, N., \& Setyawan, A. (2019, December 17). Fire Mitigation Boardgame for Elementary Student at Sintang Region. Proceedings of the 2nd International Conference on Social Sciences and Interdisciplinary Studies (formerly ICCSSIS), ICCSIS 2019, 24-25 October 2019, Medan, North Sumatera, Indonesia. https://eudl.eu/doi/10.4108/eai.24-102019.2290556 